RAP CONFERENCE PROCEEDINGS, VOL. 5, PP. 72-74, 2020

ISSN 2737-9973 (ONLINE)| DOI: 10.37392/RAPPROC.2020.17

RAP-PROCEEDINGS.ORG

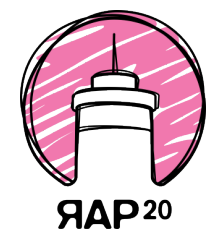

\title{
FUKUSHIMA NUCLEAR DISASTER
}

\author{
Masaki Tan* \\ NAKADA Geriatric Health and Welfare Facilities, Miyagi, Japan
}

\begin{abstract}
In this brief communication, some considerations related to Fukushima nuclear disaster are presented. They analyse the roles of public and private institutions in the crisis management of the accident. This topic is still under attention because the consequences of radiation on people, environment, and the whole planet must be taken into account. This short review of the facts that happened should be a warning and a memory. Lessons have been learnt and future science should be the science of safety.
\end{abstract}

Keywords: Fukushima, earthquake, tsunami, accident, disaster

\section{INTRODUCTION}

On Friday, 11 March 2011, at 14:46, the 9.0 Mw Tohoku Earthquake occurred, with an epicenter near Honshu Island. The disaster was the most severe accident since April 1986 Chernobyl disaster and with it, the only disaster to be given INES 7 - following the Classification of the International Nuclear Event Scale [1]. Its direct causes were all foreseeable. The report discovered that the plant was incapable of withstanding the earthquake and tsunami. The plant was located in Japan which, like the rest of the Pacific Rim, is in an active seismic zone. The International Atomic Energy Agency (IAEA) had expressed concern about the ability of Japan's nuclear plants to withstand seismic activity. At a 2008 meeting of the G8's Nuclear Safety and Security Group in Tokyo, an IAEA expert warned that a strong earthquake above 7.0 could pose a serious problem for Japan's nuclear power stations. The region had experienced three earthquakes of magnitude greater than 8, including the 869 Jogan Sanriku earthquake, the 1896 Meiji-Sanriku earthquake and the 1933 Sanriku earthquake.

Fukushima plant's Reactor 1 was constructed in July 1967 and commenced operation on 26 March 1971. Reactor 2 commenced operation in July 1974, and Reactor 3 in March 1976. On 30 October 1991, one of the two backup generators of Reactor 1 failed after flooding in the reactor's basement. An engineer informed his superior of the possibility that tsunami could damage the generators. No action to mitigate the risk was taken. An in-house Tokyo Electric Power Company (TEPCO) report in 2000 recommended safety measures against seawater flooding based on the potential of a 15- meter tsunami. TEPCO ignored the report. In 2008, an in-house study mentioned the possibility of tsunami-waves of up to $\mathbf{1 0 . 2}$ meters.
Headquarters did not take the prediction seriously.

In April 2011, TEPCO declared that cooling systems for Units 1-4 were beyond repair. Unit 1 was equipped with the Isolation Condenser or IC. Unfortunately, as the tsunami engulfed the station, the IC valves were closed and could not be reopened due to the loss of power. In August 2014, TEPCO released an estimate that Reactor 3 had a complete melt through in the initial phase of the accident. According to this estimate, within the first three days of the accident, the entire core content of Reactor 3 had melted through the reactor pressure vessel RPV and fallen to the bottom of the primary containment vessel. The greater damage in Unit 1 was due to the longer time that no cooling water was injected. This resulted in much more decay heat compared to Units 2 and 3 . When the reactor is not producing electricity, its cooling pumps can be powered by other reactor units. Two emergency generators were available for each of Units 1-5 and three for Unit 6 . All six units were given access to these generators, but the switching stations that sent power from these backup generators to the reactor's cooling systems for Units 1-5 were still in the poorly protected turbine buildings. If the switching stations had been moved to inside the reactor buildings or to the other flood-proof locations, power would have been provided by these generators to the reactor's cooling system. The Fukushima reactors were not originally designed for a large tsunami nor had the reactors been modified when concerns were raised in Japan and by the IAEA.

\section{ANALYSIS}

Three investigations into the Fukushima disaster showed the man-made nature of the catastrophe and its roots in regulatory "capture" associated with a network of corruption, collusion, and nepotism. The New York Times wrote that the Japanese nuclear

*mtano621@gmail.com 
regulatory system sided with and promoted nuclear industry because of amakudari (descent from heaven) in which senior regulators accepted high paying jobs at companies they once oversaw [2]. To protect their potential future position in the industry, regulators sought to avoid taking positions that upset or embarrassed the companies. Numerous reports claim the government shares the blame with the regulatory agency for not ensuring the independence of the oversight function.

The National Diet of Japan Fukushima Nuclear Accident Independent Investigation Commission (NAIIC) was the first independent commission by the National Diet in the 66-year history of Japan's constitutional government. Fukushima Nuclear Disaster was a profoundly man-made disaster that could and should have been foreseen and prevented. Also, its effects could have been mitigated by a more effective human response. Governments, regulatory authorities, and TEPCO lacked a sense of responsibility to protect people's lives and society. They effectively betrayed the nation's right to be safe from nuclear accidents [3]. The Investigation Committee on the Accident at Fukushima Nuclear Power Stations (ICANPS) was created to identify the disaster's causes and propose policies designed to minimize the damage and prevent recurrence of similar incidents. The panel's report [4] faulted an inadequate legal system for nuclear crisis management. The panel concluded that a culture of complacency about nuclear safety and poor crisis management led to the nuclear disaster.

Regulatory capture refers to the situation where regulators charged with promoting the public interest deferring to the wishes and advancing the agenda of the industry or sector they ostensibly regulate. Regulatory capture explains why some of the risks of operating nuclear power reactors in Japan were systematically downplayed and mismanaged so as to compromise operational safety.

The Fukushima coast has some of the world's strongest currents and these have transported contaminated waters far into the Pacific Ocean. The results of measurements of occasional sediments led to the supposition that the consequences of the accident, in terms of radioactivity, would be minor for marine life, as of autumn 2011. Despite Cesium isotopic concentration in the waters of Japan, radiation risks are below what is generally considered harmful to animals and human consumers. However, in the days after the accident, radiation released to the atmosphere forced the government to declare an ever larger evacuation zone around the plant, culminating in an evacuation zone with a $20-\mathrm{km}$ radius. Some 154,000 residents were evacuated from the communities surrounding the plant due to the rising of off-site levels of ambient ionizing radiation caused by airborne radioactive contamination from the damaged reactors.

2012 crops did not show signs of radioactivity contamination. Fukushima-produced rice was accepted by consumers as safe. In March 2014, numerous news sources announced that radiation would not be a health hazard for North American residents. Total radiation exposure was deemed safe. Atmospheric radiation has been monitored continuously [5,6].

Although there were no deaths from radiation exposure in the immediate aftermath of the incident, there were a number of non-radiation related deaths during the evacuation of the nearby population. Approximately 18,500 people died due to the earthquake and tsunami. Government agencies and TEPCO were unprepared for the cascading nuclear disaster. Tsunami that started the nuclear disaster could and should have been anticipated. In March 2012, Prime Minister Noda said that the government shared the blame for the Fukushima disaster, saying that officials had been blinded by a false belief in the country's technological infallibility and taken in by a safety myth. Noda said everybody must share the pain of responsibility. One of the most obvious lessons was that, in tsunami-prone areas, a power station's seawall must be adequately tall and robust. At the Onagawa plant, closer to the epicenter of 11 March earthquake and tsunami, the seawall was 14 meters high, and it successfully withstood the tsunami, preventing serious damage and radioactivity release. It provides evidence that it is possible for a properly designed and operated nuclear facility to withstand such a cataclysm. Three months after the disaster, at a meeting in Vienna, the IAEA faulted lax oversight by the Ministry of Economy, Trade and Industry, saying that the Ministry was in charge of both regulating and promoting the nuclear power industry.

According to former Prime Minister Naoto Kan, the country was unprepared for the disaster and nuclear power plants should not have been built so close to the ocean. Kan acknowledged flaws in authorities' handling of the crisis, including poor communication and coordination between nuclear regulators, utility officials and the government. He said the disaster laid bare a host of even bigger man-made vulnerability in Japan's nuclear industry and regulation from inadequate safety guidelines to crisis, all of which he said needed to be overhauled.

Amory Lovins, an American writer, physicist, and environmentalist, said that Japan's bureaucratic structures, reluctance to send bad news upwards, a need to save face, eagerness to preserve nuclear power's public acceptance, and politically fragile government, along with TEPCO's very hierarchical management culture, also contributed to the way the accident unfold. The information to Japanese people about nuclear energy had been tightly controlled by both TEPCO and the government.

TEPCO's position as the largest utility in Japan made it the most desirable position for retiring regulators. To protect their potential future positions in the industry, regulators sought to avoid taking positions that upset or embarrassed the companies. In 2002, TEPCO admitted falsifying safety records for Unit 1. A lead GE designer warned about major design flaws in 1976. A power board distributing electricity to temperature control valves had not been examined for 11 years. Inspections did not cover cooling systems, such as water pump motors and diesel generators. In 2011, an engineer informed his superiors of the possibility that a tsunami could have damaged the 
generators. TEPCO failed to meet the most basic safety requirements, such as assessing the probability of damage, preparing for containing collateral damage from such a disaster, and developing evacuation plans.

On 12 October 2012, TEPCO admitted for the first time that it had failed to take stronger measures to prevent disasters for fear of inviting lawsuits or protesters against the nuclear plants. There are no clear plans for decommissioning the plant, but the plant management estimate it will happen in thirty or forty years.

Emails from the Nuclear and Industrial Safety Agency to Fukushima covering a period from 12 March at $11: 54 \mathrm{pm}$ to $16 \mathrm{March}$ at $9 \mathrm{am}$ and holding vital information for evacuation and health advisers went unread and were deleted. The data was not used because the disaster countermeasure office regarded the data as useless because the predicted amount of released radiation was unrealistic. Japan's response was flawed by poor communications and delays in releasing data on dangerous radiation leaks at the facility.

Poor planning worsened the disaster response as authorities had grossly underestimated the risk of tsunami after the magnitude 9.0 earthquake. The 12.1-meter high tsunami that struck the plant was double the height of the highest wave predicted by the officials. An erroneous assumption about the plant's cooling function after the tsunami worsened the disaster. Plant workers had no clear instructions on how to respond to such a disaster, causing miscommunication, especially when the disaster destroyed backup generators. The Rebuild Japan Initiative Foundation described how Japan's response was hindered by a loss of trust between the major actors: the Prime Minister, TEPCO, and the plant manager. These conflicts produced confused flows of contradictory information. A 2012 report in The Economist stated that the operating company was poorly regulated and did not know what was going on. The operators made mistakes. The representatives of the safety inspectors fled. The establishment repeatedly played down the risks and suppressed information about the movement of the radioactive plume, resulting in the relocation of some people from safer to more contaminated areas. From 17 to 19 March 2011, a US military aircraft measured radiation within $45-\mathrm{km}$ radius of the site. US provided the data to the Japanese Ministry of Economy, Trade and Industry on 18 March but an official did not act on the information. The data were not forwarded to the prime minister's office nor were they used to direct the evacuation.

Government and TEPCO were unprepared for the cascading nuclear disaster. The tsunami that began the nuclear disaster had been anticipated and that ambiguity about the roles of public and private institutions in such a crisis was a factor in the poor response.

\section{CONCLUSION}

In March 2012, Japanese Prime Minister Noda pointed out that the government, among others, was responsible for Fukushima disaster. During the tsunami, Naoto Kan, Japan's Prime Minister, admitted that the country was unprepared for the disasters, mentioning many weak points. Amory Lovins emphasized rigid bureaucratic structures and analyzed the role of TEPCO and the government. Despite the disasters that happened, we must save our wonderful earth like Pripyat in Ukraine and Fukushima in Japan.

We experienced the greatest disaster of Fukushima Nuclear Accident (level INES 7). There are many lessons to learn: the fragility of human life, its vulnerability, man's omnipotence and helplessness. We live in the age of atoms. It is absolutely necessary to prevent man-made disasters because the most important reasons and purposes of human being are peace and happiness. Future science should be the science of safety. Humanity's greatest strength is our ability to dream of a better world, to imagine the future, and inspire generations to bring life. Let there be life!

\section{REFERENCES}

1. International Nuclear and Radiological Event Scale (INES), IAEA, Vienna, Austria, 1990.

Retrieved from:

https://www.iaea.org/resources/databases/internati onal-nuclear-and-radiological-event-scale

Retrieved on: Jan. 21, 2020

2. N. Onishi, K. Belson, "Culture of Complicity Tied to Stricken Nuclear Plant," The New York Times, Apr. 26, 2011.

Retrieved from: https://www.nytimes.com/2011/04/27/world/asia/ 27collusion.html

Retrieved on: Jan. 23, 2020

3. The official report of The Fukushima Nuclear Accident Independent Investigation Commission, The National Diet of Japan, Tokyo, Japan, 2012. Retrieved from:

https://web.archive.org/web/20120710075620/http ://naiic.go.jp/wpcontent/uploads/2012/07/NAIIC report lo res.pdf Retrieved on: Jan. 25, 2020

4. Final report, Investigation Committee on the Accident at the Fukushima Nuclear Power Stations of Tokyo Electric Power Company, Tokyo, Japan, 2012.

Retrieved from:

https://www.cas.go.jp/jp/seisaku/icanps/eng/finalreport.html

Retrieved on: Jan. 31, 2020

5. Z. Zhang et al., "Atmospheric Activity Concentration of $90 \mathrm{Sr}$ and $137 \mathrm{Cs}$ after the Fukushima Daiichi Nuclear Accident," Environ. Sci. Technol., vol. 52, no. 17, pp. 9917 - 9925, Sep. 2018.

DOI: $10.1021 /$ acs.est.8bo1697 PMid: 30080962

6. K. Hirose, "Atmospheric effects of Fukushima nuclear accident: A review from a sight of atmospheric monitoring," J. Environ. Radioact., vol. 218, article no. 106240, Jul. 2020. DOI: 10.1016/j.jenvrad.2020.106240 PMid: 32421574 